\title{
Displacement current phenomena in the magnetically insulated transmission lines of the refurbished $Z$ accelerator
}

\author{
R. D. McBride, ${ }^{1}$ C. A. Jennings, ${ }_{1}^{1}$ R. A. Vesey, ${ }^{1}$ G. A. Rochau, ${ }^{1}$ M.E. Savage, ${ }^{1}$ W. A. Stygar, \\ M.E. Cuneo, ${ }^{1}$ D. B. Sinars, ${ }^{1}$ M. Jones,${ }^{1}$ K. R. LeChien, ${ }^{1}$ M. R. Lopez, ${ }^{1}$ J. K. Moore, ${ }^{2}$ \\ K. W. Struve, ${ }^{1}$ T. C. Wagoner, ${ }^{2}$ and E. M. Waisman ${ }^{1}$ \\ ${ }^{1}$ Sandia National Laboratories, Albuquerque, New Mexico 87185, USA \\ ${ }^{2}$ Ktech Corporation, Albuquerque, New Mexico 87123, USA \\ (Received 15 September 2010; published 27 December 2010)
}

Experimental data is presented that illustrates important displacement current phenomena in the magnetically insulated transmission lines (MITLs) of the refurbished $Z$ accelerator [D. V. Rose et al., Phys. Rev. ST Accel. Beams 13, 010402 (2010)]. Specifically, we show how displacement current in the MITLs causes significant differences between the accelerator current measured at the vacuuminsulator stack (at a radial position of about $1.6 \mathrm{~m}$ from the $Z$ axis of symmetry) and the accelerator current measured at the load (at a radial position of about $6 \mathrm{~cm}$ from the $Z$ axis of symmetry). The importance of accounting for these differences was first emphasized by Jennings et al. [C. A. Jennings et al., IEEE Trans. Plasma Sci. 38, 529 (2010)], who calculated them using a full transmission-lineequivalent model of the four-level MITL system. However, in the data presented by Jennings et al., many of the interesting displacement current phenomena were obscured by parasitic current losses that occurred between the vacuum-insulator stack and the load (e.g., electron flow across the anode-cathode gap). By contrast, the data presented herein contain very little parasitic current loss, and thus for these low-loss experiments we are able to demonstrate that the differences between the current measured at the stack and the current measured at the load are due primarily to the displacement current that results from the shunt capacitance of the MITLs (about $8.41 \mathrm{nF}$ total). Demonstrating this is important because displacement current is an energy storage mechanism, where energy is stored in the MITL electric fields and can later be used by the system. Thus, even for higher-loss experiments, the differences between the current measured at the stack and the current measured at the load are often largely due to energy storage and subsequent release, as opposed to being due solely to some combination of measurement error and current loss in the MITLs and/or double post-hole convolute. Displacement current also explains why the current measured downstream of the MITLs (i.e., the load current) often exceeds the current measured upstream of the MITLs (i.e., the stack current) at various times in the power pulse (this particular phenomenon was initially thought to be due to timing and/or calibration errors). To facilitate a better understanding of these phenomena, we also introduce and analyze a simple $L C$ circuit model of the MITLs. This model is easily implemented as a simple drive circuit in simulation codes, which has now been done for the LASNEX code [G. B. Zimmerman and W. L. Kruer, Comments Plasma Phys. Controlled Fusion 2, 51 (1975)] at Sandia, as well as for simpler MATLAB ${ }^{\circledR}$-based codes at Sandia. An example of this $L C$ model used as a drive circuit will also be presented.

DOI: 10.1103/PhysRevSTAB.13.120401

PACS numbers: 52.58.Lq, 84.70.+p

\section{INTRODUCTION}

The refurbished $Z$ pulsed-power accelerator [1,2] delivers approximately 4-MV, 26-MA, 100-600-ns electrical pulses to various loads for research efforts in inertial confinement fusion [3-7], pulsed-power physics [8], $z$-pinch physics [9,10], radiation effects [11], radiation physics [12,13], laboratory astrophysics [14], dynamic materials [15-17], and other high-energy-density physics applications $[4,18]$.
The architecture of the refurbished $Z$ accelerator is discussed in detail in Ref. [2]. ${ }^{1}$ It is based on thirty-six Marx-generator/pulse-forming-line modules connected electrically in parallel (Fig. 1). Each of the thirty-six

\footnotetext{
${ }^{1}$ Reference [2] is on the 3D electromagnetic modeling of the principal components of $Z$ using the LSP code [19-21]. The models of the various components are combined to run simulations of $Z$ as a single system. Because all of the principal components of $Z$ are considered, Ref. [2] also provides a thorough description of the refurbished $Z$ accelerator.
} 
Marx generators contains sixty $2.6-\mu \mathrm{F}$ capacitors. When the capacitors are charged to $90 \mathrm{kV}, Z$ stores approximately $23 \mathrm{MJ}$ of electrical energy.

Since $Z$ is a pulsed-power accelerator, various stages are necessary for achieving pulse compression and power amplification, as well as pulse-shaping capabilities. Referring to Fig. 1, we see that each Marx generator is discharged into a coaxial intermediate storage capacitor (ISC). Each ISC is subsequently discharged through a laser-triggered gas switch (LTGS) into a coaxial pulseforming line (PFL). Each PFL is discharged through a self-breaking main water switch into an output transmission line (OTL1). Each OTL1 is discharged through a peaking water switch into a second output transmission line (OTL2). The OTL2s combine pairs of OTL1 outputs into single OTL2 outputs that feed the water convolute. The water convolute then makes the connection from the eighteen OTL2 outputs to the four electrically parallel levels of the vacuum-insulator stack.

The vacuum-insulator stack is connected to four electrically parallel vacuum magnetically insulated transmission lines (MITLs) [22]. The four MITLs are then connected to a single inner-MITL feed by a double post-hole convolute. Finally, the inner-MITL feed connects to the experimental load under test (e.g., a $z$-pinch target).

At the vacuum-insulator stack, which is at a radial position of about $1.6 \mathrm{~m}$ from the $Z$ axis of symmetry, voltage $(\dot{D})$ and current $(\dot{B})$ measurements are made on all four levels and at multiple azimuthal locations (Fig. 2) $[23,24]$. Current $(\dot{B})$ measurements are also made near the

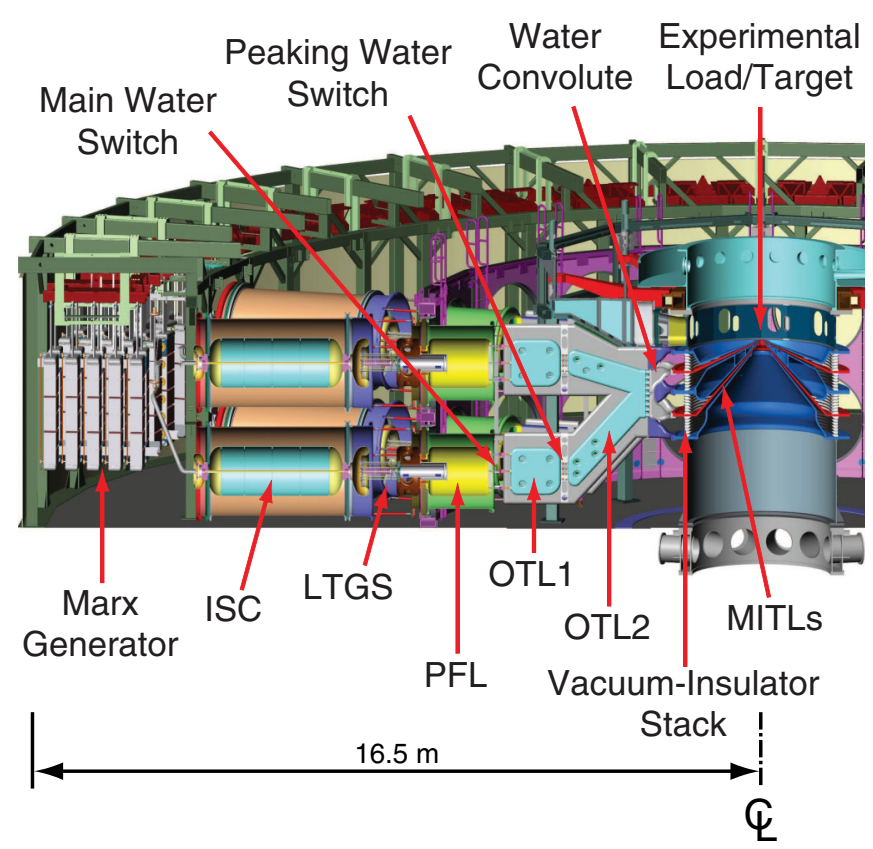

FIG. 1. Cross-sectional drawing of one radial half of the refurbished $Z$ pulsed-power accelerator. The various components/stages are described in the text.

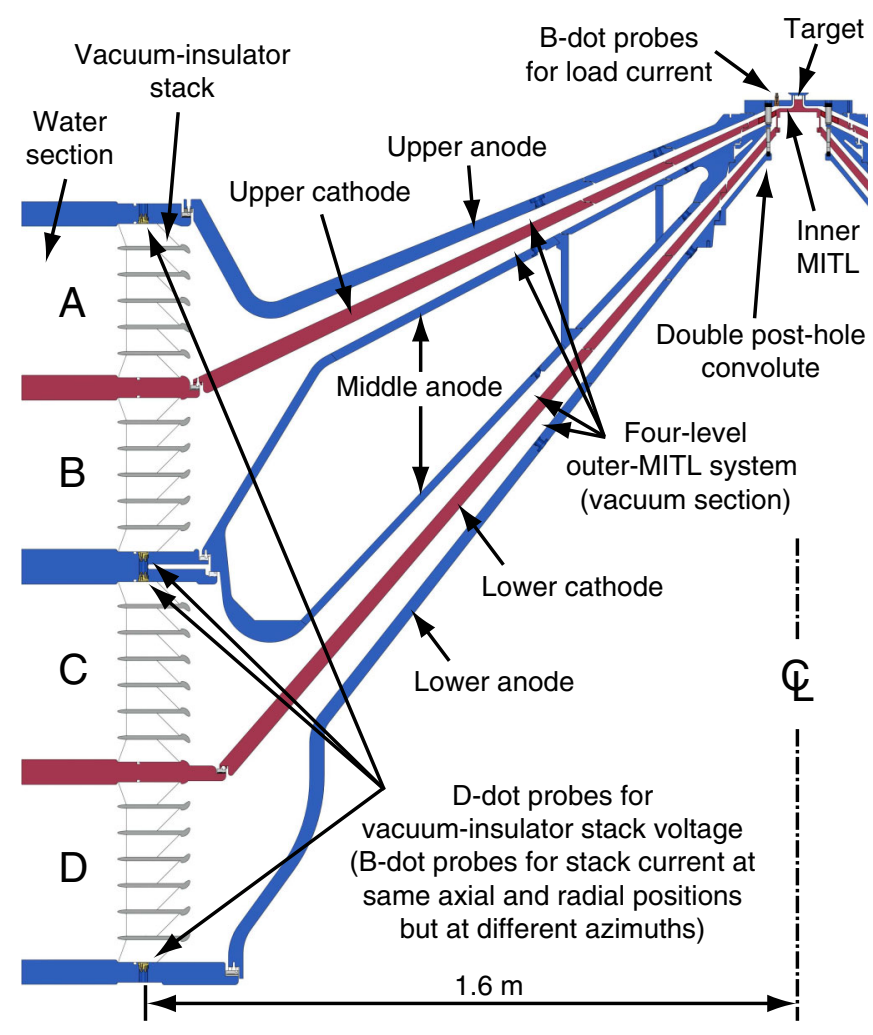

FIG. 2. Cross-sectional drawing of one radial half of the refurbished $Z$ vacuum section.

experimental load, at a radial position of about $6 \mathrm{~cm}$ from the $Z$ axis of symmetry, and again at multiple azimuthal angles (Fig. 2) [23,25]. For the experiments presented in this paper, approximately sixteen $\dot{D}$ and sixteen $\dot{B}$ probes were used on each of the four levels of the vacuuminsulator stack, and six $\dot{B}$ probes were used at the load. Because of the number of probes used, the relative $2 \sigma$ random uncertainty is about $1 \%$ for the voltage and current measured at the stack, and about 3\% for the current measured at the load [23]. ${ }^{2}$

When the waveform of the current measured at the stack is compared with the waveform of the current measured at the load, there can be substantial differences due to current losses between the two measurement locations, particularly in the double post-hole convolute region [26-28]. However, data from experiments with very little current loss reveal some interesting peculiarities about these measured differences. For example, the data shown in Fig. 3 indicate that there are times when the downstream current

\footnotetext{
${ }^{2}$ The stack and load electrical measurements presented in this paper have been time shifted relative to each other by -0.75 and $+0.75 \mathrm{~ns}$, respectively, to account for a systematic error in signal cross timing. These shifts are reasonable given the expected 1-ns accuracy of cable timings, and they hold constant throughout the analysis of this data set (six experiments). Thus, these shifts should not impact any of the conclusions found in this paper.
} 


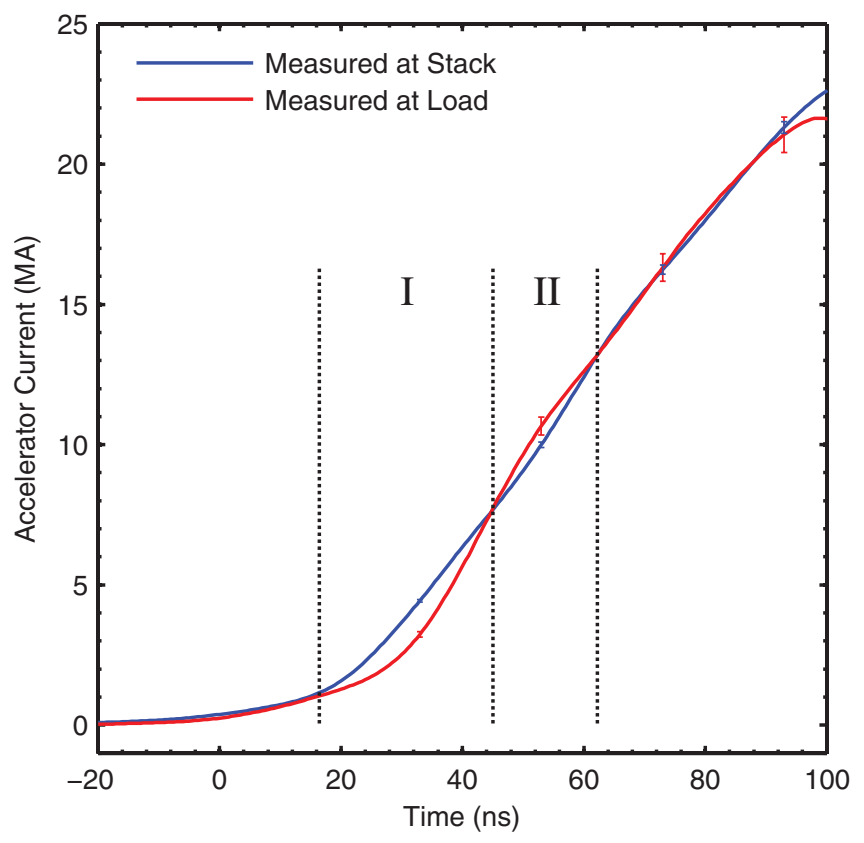

FIG. 3. A low-loss example of the $Z$ accelerator current measured at the vacuum-insulator stack and measured at the load. The error bars plotted at four times $(33,53,73$, and $93 \mathrm{~ns})$ show the relative $\pm 2 \sigma$ random uncertainty in the measurements (i.e., $\pm 1 \%$ for the stack current and $\pm 3 \%$ for the load current). Thus, we are confident that we are able to resolve the subtle differences between the stack and load currents, particularly early in the pulse (i.e., regions I and II).

(i.e., the load current) exceeds the upstream current (i.e., the stack current).

These differences (e.g., regions I and II in the low-loss example of Fig. 3) were initially suspected to be due to a combination of measurement error and current loss in the MITLs and double post-hole convolute. That is, it was thought that the downstream current should always be less than or equal to the upstream current, where the inequality holds if there are losses and the equality holds if there are no losses. This is understandable since a Thevenin-equivalent representation such as the one shown in Fig. 4 has commonly been used for interpreting measured data on $Z$ and for driving simulations of $Z$ experiments [29]. Thus, when interpreting the waveforms shown in Fig. 3, it was thought that there must be a timing and/or calibration error in the measurements to explain the times when the downstream current exceeds the upstream current. Furthermore, the differences in the two waveform shapes were interpreted as current losses between the two measurement locations. Indeed this is largely true for higher-loss experiments. But it was eventually shown by Jennings et al. in Ref. [26] that a significant portion of these differences could be accounted for in a lossless fashion by using a full transmission-line-equivalent (TLE) model of the four-level MITL system (similar

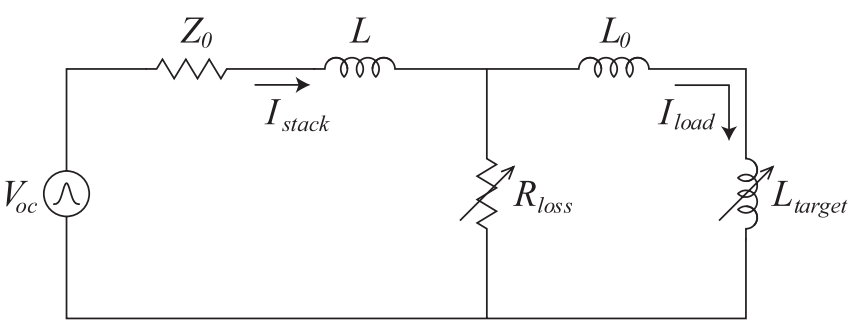

FIG. 4. The Thevenin-equivalent circuit representation of $Z$ that has commonly been used for driving simulations and interpreting data from experiments. The averages of the current measurements made at the vacuum-insulator stack and the load are represented by $I_{\text {stack }}$ and $I_{\text {load }}$, respectively, while $V_{\mathrm{oc}}(t)$ is the $Z$ open-circuit source voltage, $Z_{0}$ is the accelerator impedance, $L$ is the MITL inductance, $R_{\text {loss }}(t)$ is a resistive element for modeling parasitic current losses from electron flow across the anode-cathode gap prior to the load, $L_{0}$ is the inductance of the double post-hole convolute and inner-MITL feed, and $L_{\text {target }}(t)$ is the dynamic inductance of the target. This circuit is derived from more sophisticated pulsed-power simulations that model all major components of the $Z$ accelerator [29,39]. Note that this representation does not include an element for displacement current. Thus, this representation implies that $I_{\text {load }} \leq I_{\text {stack }}$ for all time, which is clearly inconsistent with the data shown in Fig. 3.

TLE methods have been used in the past; see, for example, Refs. [22,30,31]). However, in the data presented by Jennings et al., many of the interesting displacement current phenomena were obscured by parasitic current losses that occurred between the vacuum-insulator stack and the load (e.g., electron flow across the anode-cathode gap). ${ }^{3}$ By contrast, the data presented herein contain very little parasitic current loss, and thus for these low-loss experiments, we will demonstrate that the differences between the current measured at the stack and the current measured at the load are due primarily to the displacement current that results from the shunt capacitance of the MITLs (about $8.41 \mathrm{nF}$ total).

The remainder of this paper is organized as follows. In Sec. II, we demonstrate that, for the low-loss data shown in Fig. 3, the differences between the current measured at the stack and the current measured at the load are accounted for using a lossless propagation model (i.e., using the full TLE method of Ref. [26] with the loss mechanisms turned off). In Sec. III, we introduce a simple $L C$ model of the $Z$ MITLs to aid in the explanation of the observed phenomena. In Sec. IV, we demonstrate the use of this $L C$ model as a simple drive circuit for simulation codes. In Sec. V, we summarize our findings.

\footnotetext{
${ }^{3}$ In fact, much of Ref. [26] is devoted to characterizing, modeling, and simulating the parasitic current losses of that data set.
} 


\section{ANALYSIS USING A FULL TRANSMISSION- LINE-EQUIVALENT MODEL}

For the low-loss experiments presented in this paper, when using the full lossless TLE method of Ref. [26] to translate the stack measurements to the position of the load-current measurements, waveform agreement such as that displayed in Fig. 5 is obtained. This shows that the load current can indeed exceed the stack current at various times during the power pulse. This particular phenomenon was not apparent in the data set of Ref. [26] because the parasitic current losses were sufficient for the measured load current to always be less than the measured stack current. By contrast, the parasitic current loss in the data presented in this paper is so small that the phenomenon is very apparent.

Figure 5 also shows that the load current can be substantially less than the stack current even when there are no parasitic losses. This has important consequences for properly evaluating the parasitic current loss in all experiments, as was pointed out by Jennings et al. in Ref. [26]. That is, the stack measurements must first be properly translated to the location of the load-current measurements, and only then should the current losses be calculated (for example,

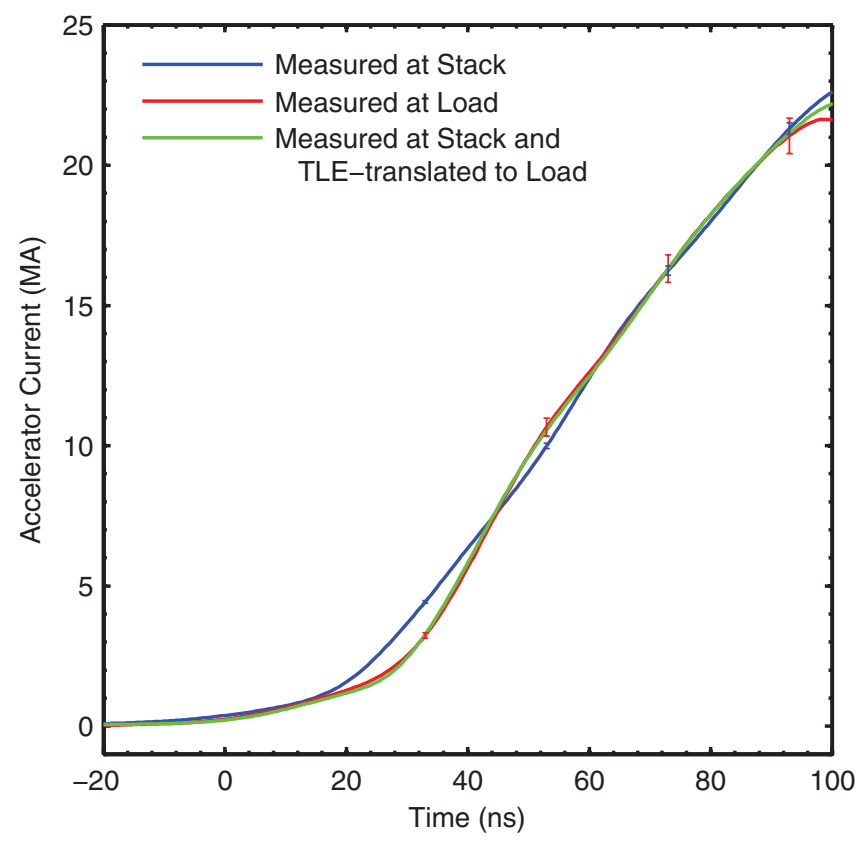

FIG. 5. The $Z$ accelerator current measured at the vacuuminsulator stack and then translated to the position of the loadcurrent measurements using the Jennings TLE model of the refurbished $Z$ MITLs [26]. The error bars plotted at four times $(33,53,73$, and $93 \mathrm{~ns})$ show the relative $\pm 2 \sigma$ random uncertainty in the measurements (i.e., $\pm 1 \%$ for the stack current and $\pm 3 \%$ for the load current). Note that for this low-loss example, the translated stack current measurement agrees with the loadcurrent measurement to within the measurement error, giving us confidence in both the fidelity of the various independent measurements, as well as the translation procedure. by subtracting the measured load current from the lossless TLE translation of the measured stack current). This is described further in Ref. [26].

\section{EXPLANATION OF THE OBSERVED DISPLACEMENT CURRENT PHENOMENA USING A SIMPLE LC CIRCUIT MODEL}

We can more easily explain the phenomena observed in Figs. 3 and 5 by reducing the full TLE model (four parallel ladder networks each consisting of $\sim 1000$ series inductors and shunt capacitors) down to a single equivalent series inductor $(6.64 \mathrm{nH})$ and a single equivalent shunt capacitor $(8.41 \mathrm{nF}){ }^{4}$ The resulting simple circuit is shown in Fig. 6 (we will refer to this as the " $L C$ " model). This reduction is reasonable since the minimum rise time of the $Z$ accelerator current is much longer than the electromagnetic transit time in the MITLs (i.e., $100 \mathrm{~ns} \gg 6 \mathrm{~ns}$ ). ${ }^{5}$

Thus with a valid model, we proceed as follows. Since the displacement current "through" the capacitor is $C\left(d V_{C} / d t\right)$, where $V_{C}$ is the voltage across the capacitor, and $t$ is the time, we know that the resulting load current must be

$$
I_{\text {load }}=I_{\text {stack }}-C \frac{d V_{C}}{d t} .
$$

Also, since the voltage drop across the inductor $L$ is $L\left(d I_{\text {stack }} / d t\right)$, we know that the resulting voltage across the capacitor must be

$$
V_{C}=V_{\text {stack }}-L \frac{d I_{\text {stack }}}{d t} .
$$

Substituting Eq. (2) into Eq. (1), we have the $L C$-translated current at the load

$$
I_{\text {load }}=I_{\text {stack }}-C \frac{d V_{\text {stack }}}{d t}+L C \frac{d^{2} I_{\text {stack }}}{d t^{2}} .
$$

In Fig. 7, we plot the $L C$-translated current of Eq. (3) along with the measured load current and the measured

\footnotetext{
${ }^{4}$ These values were calculated assuming that the MITL gap is filled solely with vacuum. The slight time-dependent capacitive increase caused by flow electrons in the gap near the cathode was calculated and was found to have a negligible effect on our analysis. Thus, a discussion on MITL flow impedance has been omitted. However, interested readers should consult Refs. [32-35] for more on the subject.

${ }^{5}$ Should the load impedance change rapidly (i.e., on the order of the 6-ns MITL transit time or less), the full $8.41 \mathrm{nF}$ of MITL capacitance, represented by the shunt capacitor in the $L C$ model, will not be completely accessible due to transit-time isolation. Thus, care must be taken when applying and interpreting the $L C$ model in these cases. Despite this fact, it has been our experience that the load current produced using the full $8.41 \mathrm{nF}$ in the $L C$ model matches the measured load current well even at times when the load impedance is changing rapidly. Therefore in practice the model proves useful throughout the power pulse of a given experiment.
} 


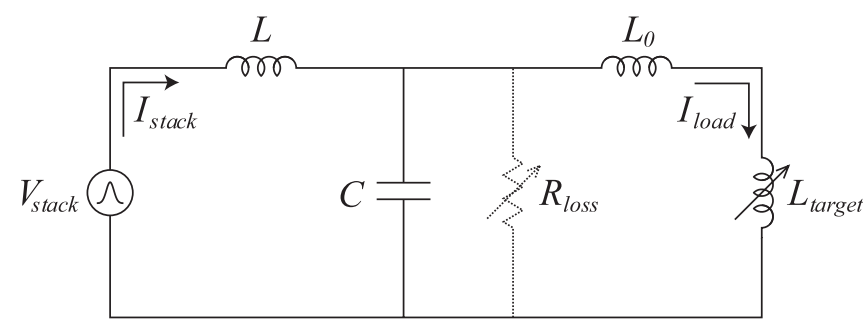

FIG. 6. Schematic of the $L C$ circuit model for $Z$. The averages of the voltage and current measurements made at the vacuuminsulator stack and the current measurements made at the load are represented by $V_{\text {stack }}, I_{\text {stack }}$, and $I_{\text {load }}$, respectively. The MITL inductance $(6.64 \mathrm{nH})$ and capacitance $(8.41 \mathrm{nF})$ are represented by $L$ and $C$, respectively, and were calculated using the electromagnetic field solver of the GORGON code [26,36,37]. The inductance of the double post-hole convolute (calculated using the QUICKSILVER code $[28,40,41]$ ) and inner-MITL feed is represented by $L_{0}$, which is about $4-6 \mathrm{nH}$ depending on the experiment. The dynamic inductance of the target is represented by $L_{\text {target }}(t)$, which is target and time dependent. Values for $L_{0}$ and $L_{\text {target }}(t)$ are, however, not required for the load-current analysis of Sec. III [see Eqs. (1)-(3)]. Also not required for our discussion is the resistive element, $R_{\text {loss }}(t)$, since we are only considering low-loss cases (for higher-loss cases, see Ref. [26]).

stack current. ${ }^{6}$ We see that the $L C$-translated and measured load-current waveforms are in good agreement in this lowloss example. That is, features such as the load current exceeding the stack current at various times are clearly captured using this model. ${ }^{7}$ From this agreement, it is clear that, for these low-loss experiments, the displacement current term in Eq. (1) is responsible for the observed differences between the current measured at the stack and the current measured at the load. Specifically, this term shows that $I_{\text {load }}<I_{\text {stack }}$ whenever $d V_{C} / d t>0$, that $I_{\text {load }}=I_{\text {stack }}$ whenever $d V_{C} / d t=0$, and that $I_{\text {load }}>I_{\text {stack }}$ whenever

\footnotetext{
${ }^{6}$ Numerical differentiation of the stack voltage and current data results in a somewhat noisy signal for the $L C$ translation (at least relative to the TLE translation shown in Fig. 5). Because of this, we have smoothed the capacitor voltage of Eq. (2) using a \pm 5 -ns moving-average filter. Later, in Sec. IV, when the $L C$ model is implemented as a drive circuit for simulations, this noise is no longer a concern due to numerical integration, and thus smoothing is not applied.

${ }^{7}$ It is worth mentioning that since the characteristic impedance is fairly constant throughout the $Z$ MITLs, similar agreement could be obtained with a single-step transmission line translation such as that described in Ref. [31]. That is, rather than dealing with the $\sim 1000$ elements of the full TLE translation, or the numerically differentiated data of the $L C$ translation, we could use
}

$$
\begin{aligned}
I_{\text {load }}= & \frac{1}{2}\left[I_{\text {stack }}(t-\tau)+I_{\text {stack }}(t+\tau)\right]+\frac{1}{2 Z}\left[V_{\text {stack }}(t-\tau)\right. \\
& \left.-V_{\text {stack }}(t+\tau)\right],
\end{aligned}
$$

where $\tau=\sqrt{L C}$ and $Z=\sqrt{L / C}$.

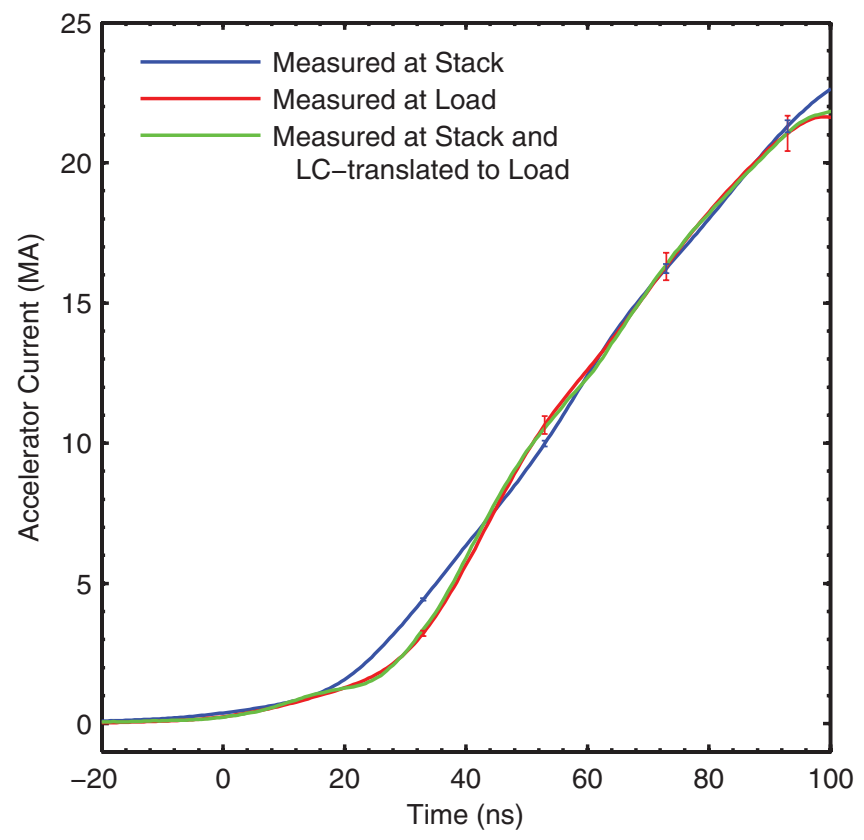

FIG. 7. The $Z$ accelerator current measured at the vacuuminsulator stack and then translated to the position of the loadcurrent measurements using the $L C$ translation of Eqs. (1)-(3). The error bars plotted at four times $(33,53,73$, and $93 \mathrm{~ns})$ show the relative $\pm 2 \sigma$ random uncertainty in the measurements (i.e., $\pm 1 \%$ for the stack current and $\pm 3 \%$ for the load current). In formulating the stack-to-load translation in this manner, some key insights are gained, as discussed in the text.

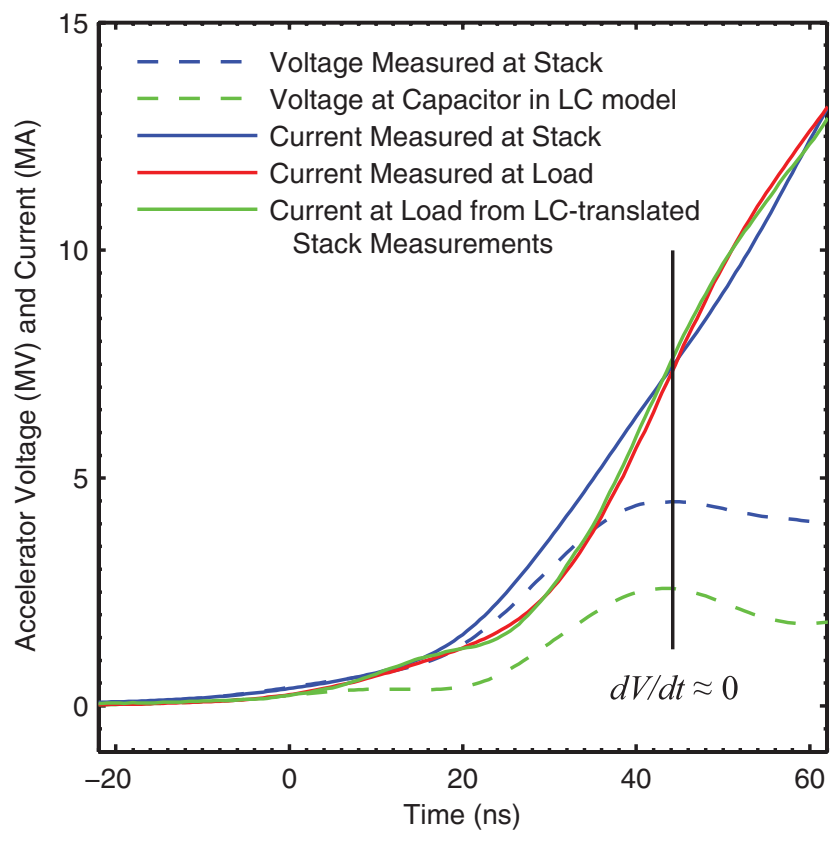

FIG. 8. A low-loss example of the stack, load, and $L C$-translated accelerator currents and their relationship to the stack and capacitor voltages in the $L C$ model. 


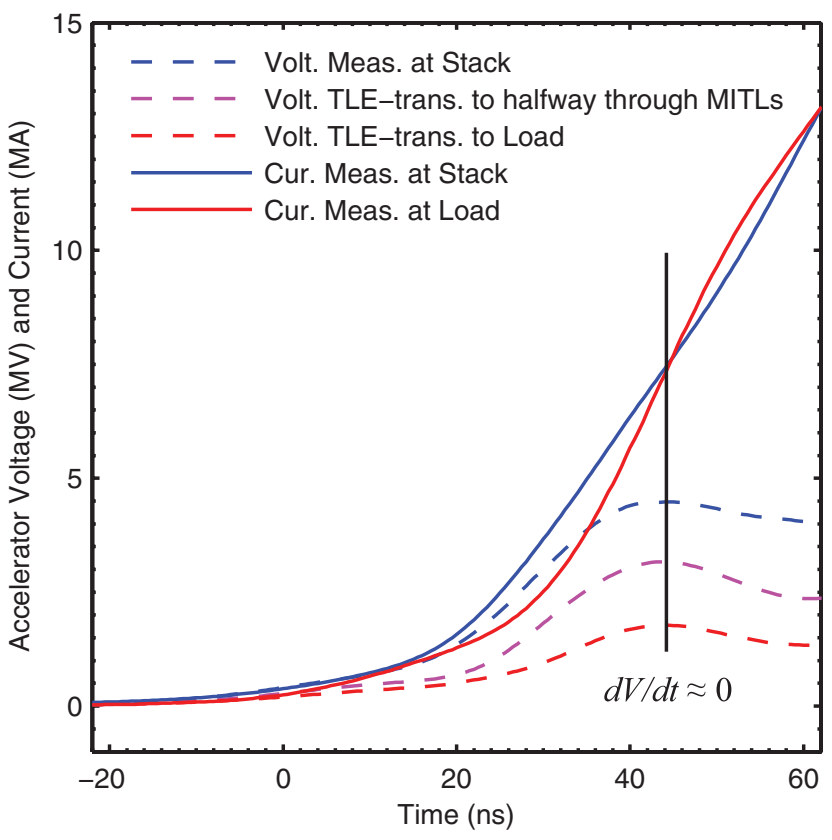

FIG. 9. A low-loss example of the stack and load accelerator currents and their relationship to the voltages throughout the MITLs. The two measured current waveforms cross each other when $d V / d t \approx 0$ throughout the MITLs because the MITL displacement current is approximately zero when $d V / d t \approx 0$ throughout the MITLs. (The translated voltages were calculated using the lossless TLE model of Ref. [26].)

$d V_{C} / d t<0$. These voltage-current characteristics are illustrated in Fig. 8.

From the preceding relationships, the following picture emerges. Early in the power pulse, while the voltage is rising $\left(d V_{C} / d t>0\right)$, the MITL capacitance is charged by some of the stack current, and therefore the load current is less than the stack current. Eventually, the voltage levels off $\left(d V_{C} / d t \approx 0\right)$, MITL charging ceases, and the stack current is equal to the load current. Finally, as the voltage falls $\left(d V_{C} / d t<0\right)$, the MITL capacitance discharges, supplying a displacement current that reinforces the stack current, and thus the load current exceeds the stack current.

Since we have substituted a single capacitor for a distributed MITL capacitance, it is somewhat unclear whether $V_{C}(t)$ adequately represents the voltage characteristics throughout the MITLs. But by using the full TLE model of Ref. [26], we find that $d V / d t \approx 0$ at about the same time throughout the MITLs, and thus the picture described above remains unchanged. This verification is shown in Fig. 9, where the voltages at three different locations, the stack, the load, and about halfway through the MITLs, have been plotted. We see that the waveform of the current measured at the load crosses over the waveform of the current measured at the stack when $d V / d t \approx 0$ throughout the MITLs. Thus, this crossover point is well understood.

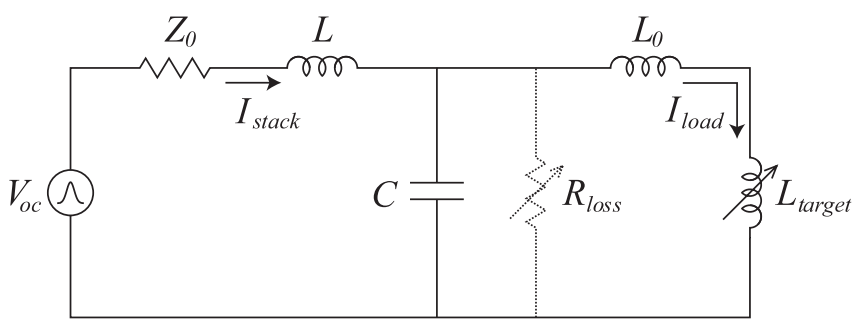

FIG. 10. Schematic of the $L C$ model implemented as a drive circuit for $Z$ simulations (essentially a simplified version of that discussed in Ref. [26]). The components are the same as those described in Fig. 6, with the exception of the $Z$ open-circuit voltage, $V_{\mathrm{oc}}(t)$ (Fig. 11), and the $Z$ accelerator impedance, $Z_{0}$ (about $0.18 \Omega$ ). The resistive element, $R_{\text {loss }}(t)$, is not required for our discussion since we are only considering low-loss cases (for higher-loss cases, see Ref. [26]).

\section{THE LC MODEL AS A SIMPLE DRIVE CIRCUIT}

Having verified that the $L C$ model adequately represents the $Z$ MITLs, we can use the model as a simple drive circuit for simulations. The schematic for this is shown in Fig. 10 (this is essentially a reduced version of the more sophisticated drive circuit discussed in Ref. [26] for $Z$ simulations using the GORGON code $[26,36,37])$. By using a drive circuit, simulations are driven solely by an opencircuit voltage waveform, such as the one shown in Fig. 11. This waveform can be constructed from the stack measurements of a previous $Z$ experiment as follows:

$$
V_{\text {oc }}(t)=2 V_{f}(t)=V_{\text {stack }}+Z_{0} I_{\text {stack }},
$$

where $V_{f}(t)$ is the forward-going voltage at the stack.

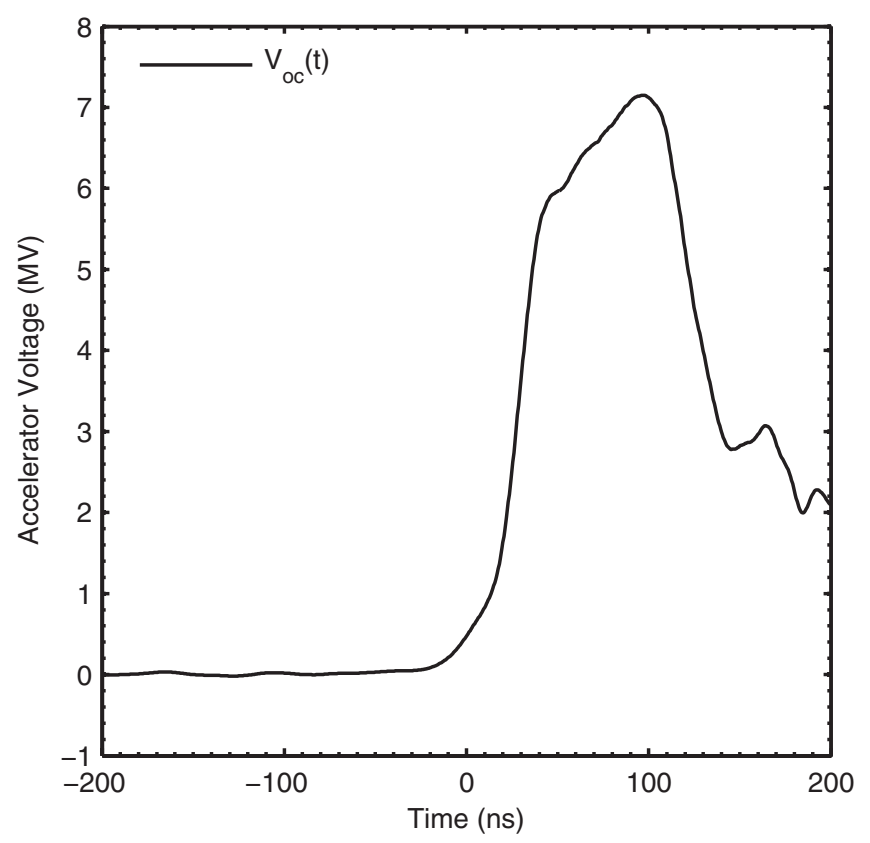

FIG. 11. Example $Z$ open-circuit voltage waveform constructed at the vacuum-insulator stack using Eq. (4). This represents $Z$ operating in short-pulse mode (i.e., accelerator current rise times of about $100 \mathrm{~ns}$ ). 


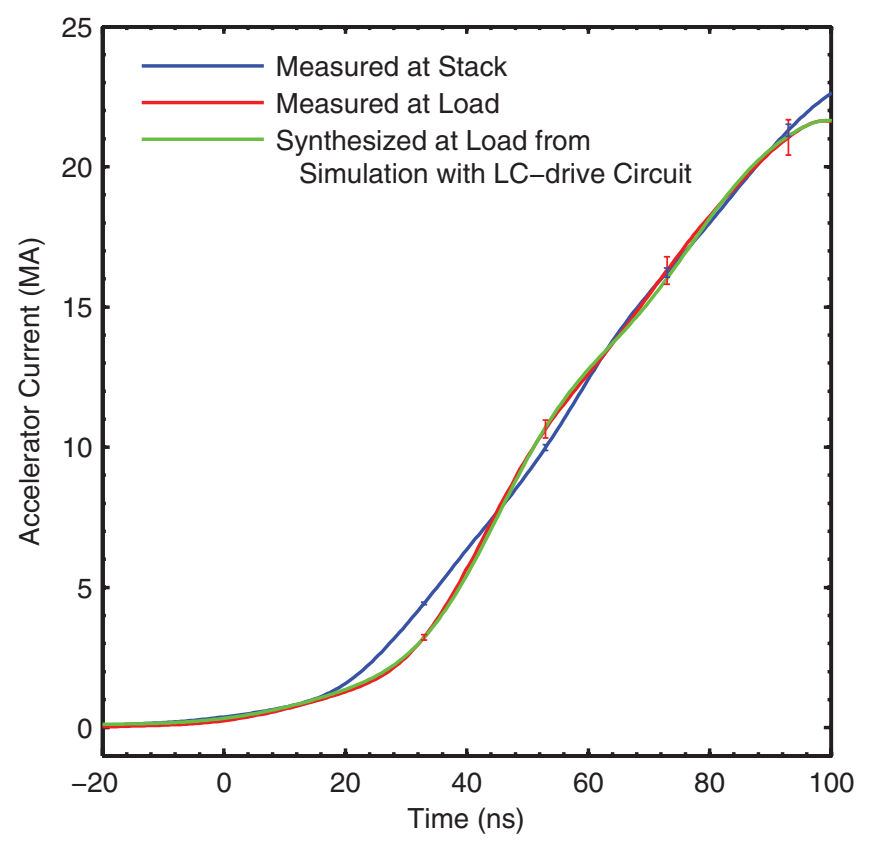

FIG. 12. The load current that is synthesized by using the $L C$ model of Fig. 10 as a drive circuit in a simulation that is driven by the $Z$ open-circuit voltage of Fig. 11 . The error bars plotted at four times $(33,53,73$, and $93 \mathrm{~ns})$ show the relative $\pm 2 \sigma$ random uncertainty in the measurements (i.e., $\pm 1 \%$ for the stack current and $\pm 3 \%$ for the load current). The synthesized load current is seen to be in excellent agreement with the measured load current. (The stack current is plotted for reference.)

The $L C$ model has now been implemented as a drive circuit for simulations using the LASNEX code [38] as well as simpler MATLAB ${ }^{\circledR}$-based simulations. A low-loss example of the agreement that can be achieved between the simulation-synthesized load current and the measured load current is shown in Fig. 12. For simulating experiments with complex loss mechanisms, a more sophisticated drive circuit should be used, such as that described by Jennings et al. in Ref. [26]. However, for many applications, this simple approach is sufficient.

\section{SUMMARY AND CONCLUSIONS}

We have presented low-loss experimental data that illustrates important displacement current phenomena in the MITLs of the refurbished $Z$ accelerator (Fig. 3). Specifically, we were able to show that displacement current in the MITLs causes significant differences between the accelerator current measured at the vacuum-insulator stack and the accelerator current measured at the load, even when there are no parasitic losses (Figs. 5-7).

An important implication of this is that displacement current must be accounted for when calculating the parasitic current loss of a given experiment, as was done by Jennings et al. in Ref. [26]. That is, the stack measurements must first be properly translated to the location of the loadcurrent measurements, and only then should the parasitic current loss be calculated (for example, by subtracting the measured load current from the lossless translation of the measured stack current). The important thing to note is that, for a given experiment, much of what could be interpreted as parasitic current loss in the MITLs and/or the double post-hole convolute is often actually energy storage in the MITL electric fields.

Moreover, we were able to explain the observed phenomenon of the downstream current (i.e., the load current) exceeding the upstream current (i.e., the stack current) in terms of displacement current. Specifically, we showed that for low-loss experiments, the shunt capacitance of the $Z$ MITLs enables the downstream current to exceed the upstream current when $d V / d t<0$, and that the downstream current is approximately equal to the upstream current when $d V / d t \approx 0$ throughout the MITLs (Figs. 8 and 9).

In conclusion then, we can say that early in the power pulse, while the voltage is rising $(d V / d t>0)$, the MITL capacitance is charged by some of the stack current, and therefore the load current is less than the stack current. Eventually, the voltage levels off $(d V / d t \approx 0)$, MITL charging ceases, and the stack current is equal to the load current. Finally, as the voltage falls $(d V / d t<0)$, the MITL capacitance discharges, supplying a displacement current that reinforces the stack current, and thus the load current exceeds the stack current.

With this understanding, the importance of including shunt capacitance in the drive-circuit models of various simulation codes becomes clear. Thus, similar to the implementation of the full four-level TLE model as a drive circuit for GORGON simulations [26], the $L C$ model has now been implemented as a drive circuit for LASNEX simulations and other simpler MATLAB ${ }^{\circledR}$-based simulations (Fig. 10). We saw that, by doing this, a simulation driven by the $Z$ open-circuit voltage (Fig. 11) resulted in a synthesized load current that was in excellent agreement with experiment (Fig. 12).

\section{ACKNOWLEDGMENTS}

The authors would like to thank M. K. Matzen, M. C. Herrmann, and J. L. Porter for programmatic support, and the $Z$ operations, diagnostics, engineering, load hardware, and target teams for their technical assistance. Sandia is a multiprogram laboratory operated by Sandia Corporation, a Lockheed-Martin company, for the United States Department of Energy's National Nuclear Security Administration, under Contract No. DE-AC0494AL85000.

[1] D. H. McDaniel, M. G. Mazarakis, D. E. Bliss, J. M. Elizondo, H. C. Harjes, H. C. Ives III, D. L. Kitterman, J.E. Maenchen, T.D. Pointon, S.E. Rosenthal, D.L. Smith, K. W. Struve, W. A. Stygar, E. A. Weinbrecht, 
D. L. Johnson, and J. P. Corley, in Proceedings of the 5th International Conference on Dense Z-Pinches, edited by C. Deeney, N. R. Pereira, and J. Davis (AIP, Melville, NY, 2002), Vol. 651, pp. 23-28.

[2] D. V. Rose, D. R. Welch, E. A. Madrid, C. L. Miller, R. E. Clark, W. A. Stygar, M.E. Savage, G. A. Rochau, J.E. Bailey, T. J. Nash, M.E. Sceiford, K.W. Struve, P. A. Corcoran, and B.A. Whitney, Phys. Rev. ST Accel. Beams 13, 010402 (2010).

[3] S. A. Slutz, M. C. Herrmann, R. A. Vesey, A. B. Sefkow, D. B. Sinars, D. C. Rovang, K. J. Peterson, and M.E. Cuneo, Phys. Plasmas 17, 056303 (2010).

[4] M. K. Matzen, M. A. Sweeney, R. G. Adams, J. R. Asay, J. E. Bailey, G. R. Bennett, D. E. Bliss, D. D. Bloomquist, T. A. Brunner, R. B. Campbell, G. A. Chandler, C. A. Coverdale, M.E. Cuneo, J.-P. Davis, C. Deeney, M.P. Desjarlais, G. L. Donovan, C. J. Garasi, T. A. Haill, C. A. Hall, D. L. Hanson, M. J. Hurst, B. Jones, M. D. Knudson, R. J. Leeper, R. W. Lemke, M. G. Mazarakis, D. H. McDaniel, T. A. Mehlhorn, T. J. Nash, C. L. Olson, J. L. Porter, P. K. Rambo, S. E. Rosenthal, G. A. Rochau, L.E. Ruggles, C. L. Ruiz, T. W. L. Sanford, J. F. Seamen, D. B. Sinars, S. A. Slutz, I. C. Smith, K. W. Struve, W. A. Stygar, R. A. Vesey, E. A. Weinbrecht, D. F. Wenger, and E. P. Yu, Phys. Plasmas 12, 055503 (2005).

[5] M. E. Cuneo, R. A. Vesey, J. L. Porter, Jr., G. A. Chandler, D. L. Fehl, T. L. Gilliland, D. L. Hanson, J. S. McGurn, P. G. Reynolds, L. E. Ruggles, H. Seamen, R. B. Spielman, K. W. Struve, W. A. Stygar, W. W. Simpson, J. A. Torres, D. F. Wenger, J. H. Hammer, P. W. Rambo, D. L. Peterson, and G. C. Idzorek, Phys. Plasmas 8, 2257 (2001).

[6] W. A. Stygar, M. E. Cuneo, R. A. Vesey, H. C. Ives, M. G. Mazarakis, G. A. Chandler, D. L. Fehl, R. J. Leeper, M. K. Matzen, D. H. McDaniel, J.S. McGurn, J. L. McKenney, D. J. Muron, C. L. Olson, J. L. Porter, J. J. Ramirez, J. F. Seamen, C. S. Speas, R. B. Spielman, K. W. Struve, J. A. Torres, E. M. Waisman, T. C. Wagoner, and T. L. Gilliland, Phys. Rev. E 72, 026404 (2005).

[7] D. B. Sinars, S. A. Slutz, M. C. Herrmann, R. D. McBride, M. E. Cuneo, K. J. Peterson, R. A. Vesey, C. Nakhleh, B. E. Blue, K. Killebrew, D. Schroen, K. Tomlinson, A. D. Edens, M. R. Lopez, I. C. Smith, J. Shores, V. Bigman, G. R. Bennett, B. W. Atherton, M. Savage, W. A. Stygar, G. T. Leifeste, and J.L. Porter, Phys. Rev. Lett. 105, 185001 (2010).

[8] W. A. Stygar, M. E. Cuneo, D. I. Headley, H. C. Ives, R. J. Leeper, M. G. Mazarakis, C. L. Olson, J. L. Porter, T. C. Wagoner, and J.R. Woodworth, Phys. Rev. ST Accel. Beams 10, 030401 (2007).

[9] M.E. Cuneo, E. M. Waisman, S. V. Lebedev, J.P. Chittenden, W. A. Stygar, G. A. Chandler, R. A. Vesey, E.P. Yu, T. J. Nash, D. E. Bliss, G.S. Sarkisov, T.C. Wagoner, G. R. Bennett, D. B. Sinars, J. L. Porter, W. W. Simpson, L. E. Ruggles, D. F. Wenger, C. J. Garasi, B. V. Oliver, R. A. Aragon, W. E. Fowler, M. C. Hettrick, G. C. Idzorek, D. Johnson, K. Keller, S. E. Lazier, J. S. McGurn, T. A. Mehlhorn, T. Moore, D. S. Nielsen, J. Pyle, S. Speas, K. W. Struve, and J. A. Torres, Phys. Rev. E 71, 046406 (2005).

[10] D. B. Sinars, R. W. Lemke, M. E. Cuneo, S. V. Lebedev, E. M. Waisman, W. A. Stygar, B. Jones, M. C. Jones, E. P.
Yu, J. L. Porter, and D. F. Wenger, Phys. Rev. Lett. 100, 145002 (2008).

[11] B. Jones, C. A. Coverdale, C. Deeney, D. B. Sinars, E. M. Waisman, M.E. Cuneo, D. J. Ampleford, P. D. LePell, K. R. Cochrane, J.W. Thornhill, J.P. Apruzese, A. Dasgupta, K. G. Whitney, R. W. Clark, and J.P. Chittenden, Phys. Plasmas 15, 122703 (2008).

[12] J. E. Bailey, G. A. Chandler, D. Cohen, M. E. Cuneo, M. E. Foord, R. F. Heeter, D. Jobe, P. W. Lake, J. J. MacFarlane, T. J. Nash, D. S. Nielson, R. Smelser, and J. Torres, Phys. Plasmas 9, 2186 (2002).

[13] G. A. Rochau, J. E. Bailey, Y. Maron, G. A. Chandler, G. S. Dunham, D. V. Fisher, V.I. Fisher, R. W. Lemke, J. J. MacFarlane, K. J. Peterson, D. G. Schroen, S. A. Slutz, and E. Stambulchik, Phys. Rev. Lett. 100, 125004 (2008).

[14] J. E. Bailey, G. A. Rochau, C. A. Iglesias, J. Abdallah, J. J. MacFarlane, I. Golovkin, P. Wang, R. C. Mancini, P. W. Lake, T. C. Moore, M. Bump, O. Garcia, and S. Mazevet, Phys. Rev. Lett. 99, 265002 (2007).

[15] D. H. Dolan, M. D. Knudson, C. A. Hall, and C. Deeney, Nature Phys. 3, 339 (2007).

[16] M. D. Knudson, D. L. Hanson, J. E. Bailey, C. A. Hall, J.R. Asay, and C. Deeney, Phys. Rev. B 69, 144209 (2004).

[17] J.-P. Davis, C. Deeney, M. D. Knudson, R. W. Lemke, T. D. Pointon, and D. E. Bliss, Phys. Plasmas 12, 056310 (2005).

[18] M. K. Matzen, Phys. Plasmas 4, 1519 (1997).

[19] LSP is a software product developed by ATK Mission Research, Albuquerque, NM 87110, with initial support from the Department of Energy SBIR Program.

[20] T. P. Hughes, R. E. Clark, and S. S. Yu, Phys. Rev. ST Accel. Beams 2, 110401 (1999).

[21] D. R. Welch, D. V. Rose, M.E. Cuneo, R. B. Campbell, and T. A. Mehlhorn, Phys. Plasmas 13, 063105 (2006).

[22] W. A. Stygar, P. A. Corcoran, H. C. Ives, R. B. Spielman, J.W. Douglas, B.A. Whitney, M.A. Mostrom, T.C. Wagoner, C.S. Speas, T.L. Gilliland, G. A. Allshouse, R.E. Clark, G.L. Donovan, T.P. Hughes, D. R. Humphreys, D. M. Jaramillo, M. F. Johnson, J. W. Kellogg, R. J. Leeper, F. W. Long, T. H. Martin, T. D. Mulville, M. D. Pelock, B. P. Peyton, J. W. Poukey, J. J. Ramirez, and P. G. Reynolds, Phys. Rev. ST Accel. Beams 12, 120401 (2009).

[23] T. C. Wagoner, W. A. Stygar, H. C. Ives, T. L. Gilliland, R. B. Spielman, M.F. Johnson, P. G. Reynolds, J. K. Moore, R. L. Mourning, D. L. Fehl, K. E. Androlewicz, J.E. Bailey, R.S. Broyles, T.A. Dinwoodie, G. L. Donovan, M.E. Dudley, K. D. Hahn, A. A. Kim, J. R. Lee, R. J. Leeper, G. T. Leifeste, J. A. Melville, J. A. Mills, L.P. Mix, W.B.S. Moore, B.P. Peyton, and J.L. Porter, Phys. Rev. ST Accel. Beams 11, 100401 (2008).

[24] W. A. Stygar, R. B. Spielman, H. C. Ives, W. B. S. Moore, J. F. Seamen, A. W. Sharpe, T. C. Wagoner, T. L. Gilliland, R. S. Broyles, J. A. Mills, T. A. Dinwoodie, J. S. Slopek, K. W. Struve, and P. G. Reynolds, in Proceedings of the 11th IEEE International Pulsed Power Conference, 1997, Baltimore, MD (IEEE, Piscataway, NJ, 1997), Vol. 2, p. 1258. 
[25] D. V. Rose, D. R. Welch, C. L. Miller, R. E. Clark, E. A. Madrid, C. B. Mostrom, T. C. Wagoner, J. K. Moore, W. A. Stygar, J.E. Bailey, T.J. Nash, G.A. Rochau, and D. B. Sinars, Phys. Rev. ST Accel. Beams 13, 040401 (2010).

[26] C.A. Jennings, J.P. Chittenden, M.E. Cuneo, W. A. Stygar, D. J. Ampleford, E. M. Waisman, M. Jones, M.E. Savage, K. R. LeChien, and T.C. Wagoner, IEEE Trans. Plasma Sci. 38, 529 (2010).

[27] D. V. Rose, D. R. Welch, T. P. Hughes, R. E. Clark, and W. A. Stygar, Phys. Rev. ST Accel. Beams 11, 060401 (2008).

[28] T. D. Pointon, W. A. Stygar, R. B. Spielman, H. C. Ives, and K. W. Struve, Phys. Plasmas 8, 4534 (2001).

[29] K. Struve, T. Martin, R. Spielman, W. Stygar, P. Corcoran, and J. Douglas, in Proceedings of the 11th IEEE Pulsed Power Conference, edited by G. Cooperstein and I. Vitkovitsky (IEEE, Piscataway, NJ, 1997), Vol. 1, pp. 162-167.

[30] E. M. Waisman, M. E. Cuneo, R. W. Lemke, D. B. Sinars, and W. A. Stygar, Phys. Plasmas 15, 042702 (2008).

[31] M.E. Savage, J.C.W. Mendel, T.W. Grasser, W.W. Simpson, and D. M. Zagar, Rev. Sci. Instrum. 61, 3812 (1990).

[32] C. W. Mendel, Jr., D. B. Seidel, and S. E. Rosenthal, Laser Part. Beams 1, 311 (1983).

[33] P. A. Miller and C. W. Mendel, Jr., J. Appl. Phys. 61, 529 (1987).
[34] C. W. Mendel, Jr. and S.E. Rosenthal, Phys. Plasmas 2, 1332 (1995).

[35] W. A. Stygar, T. C. Wagoner, H. C. Ives, P. A. Corcoran, M.E. Cuneo, J.W. Douglas, T.L. Gilliland, M.G. Mazarakis, J. J. Ramirez, J. F. Seamen, D. B. Seidel, and R. B. Spielman, Phys. Rev. ST Accel. Beams 9, 090401 (2006).

[36] J.P. Chittenden, S. V. Lebedev, C. A. Jennings, S. N. Bland, and A. Ciardi, Plasma Phys. Controlled Fusion 46, B457 (2004).

[37] A. Ciardi, S. V. Lebedev, A. Frank, E. G. Blackman, J. P. Chittenden, C. J. Jennings, D. J. Ampleford, S. N. Bland, S. C. Bott, J. Rapley, G. N. Hall, F. A. Suzuki-Vidal, A. Marocchino, T. Lery, and C. Stehle, Phys. Plasmas 14, 056501 (2007).

[38] G. B. Zimmerman and W.L. Kruer, Comments Plasma Phys. Controlled Fusion 2, 51 (1975).

[39] C. Harjes, J. Elizondo, K. Struve, L. Bennett, D. Johnson, and B. Shoup, in Proceedings of the 14th IEEE Pulsed Power Conference, edited by M. Giesselmann and A. Neuber (IEEE, Piscataway, NJ, 2003), Vol. 2, pp. 917-920.

[40] T.D. Pointon, Sandia National Laboratories Memorandum, November 17th (2008).

[41] J. P. Quintenz, D. B. Seidel, M.L. Kiefer, T. D. Pointon, R.S. Coats, S.E. Rosenthal, T.A. Mehlhorn, M.P. Desjarlais, and N. A. Krall, Laser Part. Beams 12, 283 (1994). 